\section{Questión}

Periodismo / Comunicación ISSN 1669-6581
- Av. $44 \mathrm{~N}^{\circ} 676,1^{\circ}$ piso

CP 1900 - La Plata - Argentina

(i) www.perio.unlp.edu.ar/question

\title{
EL ARTE Y LA SALUD EN TIEMPOS DE VIRTUALIDAD
}

\section{ART AND HEALTH IN TIMES OF VIRTUALITY}

\author{
Claudia Montesino / claudia.montesino@gmail.com \\ Docente y Directora de la Cátedra Libre de Narración Oral (FPyCS-UNLP) \\ Narradora Oral, Artivista declarada y confesa.
}

Cuando la avalancha informativa vinculada al COVID- 19 abrumaba con la enumeración de los países afectados; las estadísticas de contagios; la progresión de los fallecidos; la historia de las pandemias que azotaron a la humanidad; la descripción de sus síntomas; la discusión acerca de barbijo sí - barbijo no y el valor preventivo del aislamiento social obligatorio, casi imperceptiblemente -en los huecos no cubiertos por la infodemia-, las redes sociales y los medios de comunicación tradicionales comenzaron a darle lugar el valor del arte como escudo para enfrentar lo desconocido, lo que atemoriza y paraliza a los humanos. Y mucho más a los humanos encerrados en las cuatro paredes de la cuarentena.

El arte como sinónimo de vida, como símbolo de resiliencia y de unión fraterna entre las personas. El arte, en fin, como síntesis de un activismo que derribó fronteras simbólicas para fusionarnos en un sentir común: el arte nos da fortaleza para atravesar el mientras tanto de los momentos imprevistos, desconcertantes, extraordinarios.

Arte para alejar a los fantasmas, para arrimar los afectos distantes por el confinamiento forzoso, para redimir los dolores, para remediar las angustias, el arte -en definitiva- como medicina para los espíritus y los cuerpos maltrechos. 
En el mes de noviembre último, un informe de la Oficina Regional de la Organización Mundial de la Salud (OMS) para Europa concluyó que involucrarse con las diferentes manifestaciones del arte puede ser beneficioso para la salud mental y física de las personas. El organismo rector de la salud arribó a esa conclusión tras analizar la evidencia reunida en más de 900 publicaciones globales, la mayor y más completa revisión realizada hasta el momento del efecto del arte sobre la salud.

"Llevar el arte a la vida de la gente a través de actividades como bailar, cantar, ir a museos y conciertos ofrece una dimensión adicional sobre cómo podemos mejorar la salud física y mental. Los ejemplos citados en este innovador informe muestran las formas en que las artes pueden abordar complejos problemas de salud como la diabetes, la obesidad y la mala salud mental", dijo Piroska Östlin, la directora regional de la OMS para Europa al presentar el informe.

Así lo explicó la funcionaria (en inglés):

https://www.youtube.com/watch?v=rUQIFZJySYA\&feature=youtu.be

"Desde antes del nacimiento hasta el final de la vida, las artes pueden influir positivamente en la salud. Por ejemplo, los niños pequeños cuyos padres les leen antes de acostarse tienen un sueño nocturno más prolongado y una mejor concentración en la escuela. Entre los adolescentes que viven en áreas urbanas, la educación entre pares basada en el drama puede apoyar la toma de decisiones responsables, mejorar el bienestar y reducir la exposición a la violencia. Más adelante en la vida, la música puede apoyar la cognición en personas con demencia; en particular, el canto mejora la atención, la memoria episódica y la función ejecutiva", se sostuvo en el paper de la oficina europea de la OMS.

El informe también reveló que las actividades artísticas pueden utilizarse para complementar o mejorar los protocolos de tratamiento médico. Y citó como ejemplos que "se ha descubierto que escuchar música o hacer arte reduce los efectos secundarios del tratamiento contra el cáncer, como somnolencia, falta de apetito, falta de aliento y náuseas".

También citó que "las actividades artísticas en entornos de emergencia, que incluyen música, manualidades y payasadas, reducen la ansiedad, el dolor y la presión arterial, particularmente para los niños, pero también para sus padres", así como también mencionó que "la danza proporciona repetidamente mejoras clínicamente significativas en las puntuaciones motoras para las personas con enfermedad de Parkinson". 
La música que suena por streaming

En los atípicos días del encierro domiciliario, muchos hemos hallado en el streaming el bálsamo de la música reparadora. Sea en acciones individuales o bien en puestas corales ejecutadas al unísono desde distintas locaciones, viejas melodías volvieron a pasar por nuestros corazones, estremeciéndolos. También asistimos a estrenos presentados con pompa y circunstancia, una suerte de prueba del ácido para testear la aceptación del público remoto.

De las decenas de artistas nacionales que decidieron tomar contacto con su público a través de las redes sociales, sobresale el caso de Pedro Aznar, que a través de Facebook y durante viernes de marzo, abril y mayo, compartió conciertos desde su casa en los que concilió virtuosidad para la ejecución de cuerdas y teclados con la lectura de poesías y cuentos, de su autoría y de clásicos de la literatura. Una rica amalgama que los internauta celebré y compartí con otros desde quien sabe qué lugar del planeta. De esa manera el ciberespacio es escenario y es platea, donde todos ocupamos la primera fila.

Y es así como me encuentro sintiendo a Pedro tan cercano, sentado en casa, haciendo música y compartiendo sus poemas. Lo espero semana a semana y también me ordena, porque sé que tocará la puerta de mi computadora los viernes a la nochecita. ES así como para que no se me pase confundida la vida en "un eterno domingo", empiezo también a encontrar pequeños rituales para no perder la noción de tiempo- espacio.

En uno de esos viernes, el 3 de Abril para ser más exacta, cuando ya empezaba a olvidarme del afuera, transcurridos casi 70 minutos de su Facebook Live,Pedro comparte conmigo otro de sus poemas inéditos "Las cosas por su nombre", y me trae (como si en algún momento lo hubiera dejado de hacer) al aquí y ahora. Me invita, me alerta y sitúa cuando nos pide/nos pide "A llamar las cosas por su nombre y a cambiarlas de raíz, ahora que las máscaras se caen y se ven los quienes: Guardianes del mercado, ladrándole a la vida..." Y luego de escucharlo decir y cantar, me uno a los miles y miles de aplausos traducidos en likes. Me siento parte de un todo, de un todos, donde sabemos que tenemos los mismos sentires, pesares y para qué negarlo... también miedos.

Pero como lo ha certificado la OMS, no solo de música se alimenta la salud y el espíritu de las personas. El teatro, el cine, la danza o la literatura se han colado a la fuerza en nuestras casas- 
fortalezas anti virus. Las pantallas, en mil modelos y presentaciones, establecen los marcos por los que se rigen las nuevas vidas en la comunidad global, pandemia mediante.

$Y$ ellas, generosas, brillantes en la luminosidad de múltiples plataformas, se ofrecen para albergar todas las manifestaciones artísticas que nosotros, los humanos, podemos programar según nuestras preferencias e intereses. Enhorabuena, pese a que el acceso a la multitud de pantallas disponibles no se ha socializado suficientemente, como tampoco se ha socializado cabalmente el derecho a la alimentarse, a vestirse, a educarse y a trabajar de todos los humanos para asegurarse el sustento propio.

Los museos en el mouse

Refugio para añorar los cercanos tiempos en los que aviones nos depositaban en otros continentes en poco más de 10 horas de travesía celeste, en los días de encierro también echamos mano a cajas arrumbadas entre el polvo y el olvido. Así invertimos horas rescatando viejas o cercanas fotos de viajes iniciáticos, de periplos planificados por años o de aquella aventura espontánea que se materializó en un santiamén.

Desde ellas brotan sonrisas livianas y esperanzadas, muecas graciosas que no imaginaban ni por asomo este tiempo de ansiedad, miedos y muerte televisada minuto a minuto.

Me detengo en una imagen robada en el Museo Reina Sofía de Madrid, donde mi ojo en el visor y el dedo en el disparador fueron más rápidos que la advertencia del guardia. "Sin fotos, por favor", censuró el empleado harto de repetir las mismas palabras cada 10 minutos. Y ahí está, detrás de un abigarrado conjunto de espaldas y nucas -en su mayoría orientales-, la magnificencia del "Guernica" de Picasso. Volver a verlo en el papel fotográfico mate renueva el estremecimiento de aquella contemplación in situ.

Entonces irrumpe mi hija, y al observarme ensimismada en la brutal expresividad de la imagen, me dispara un "por qué ver fotos inmóviles si podés recorrer ese y los mejores museos del mundo paseando por todas sus salas con sólo mover el mouse".

Le agradezco la sugerencia, vuelvo la compu en las que paso horas y horas entre las reuniones laborales virtuales, y las clases a distancia, y enseguida aparece un menú inagotable de opciones para recorrer todos los períodos de la pintura y la escultura; las maravillas de artistas inmortalizados en sus obras pese al paso de los siglos, o bien las instalaciones más modernas 
y disruptivas de los creadores que en nuestra contemporaneidad están haciendo la futura historia del arte.

Aquí les dejo en variado recorrido por los museos más importantes del mundo: https://viajes.nationalgeographic.com.es/lifestyle/museos-mundo-visita-virtual_13248/2, debo confesar que no logré hacer todo el recorrido, pero sí fui a los que me mostraban momentos similares en otras épocas, incluso pintores que se retrataban ese tiempo de pandemias.

Payamédicos, los otros medicamentos

Quizás inspiradas en la película "Patch Adams", dirigida por Tom Shadyac.y basada en la historia real del médico Hunter Adams, en la que el entrañable Robin Williams encarnó a un médico que con monerías y payasadas atenuaba el dolor de personas internadas, en nuestro país hace al menos dos décadas que los denominados "payamédicos" alivian pesares en hospitales pediátricos y generales.

Combinando técnicas de clowns, magos, malabaristas, actores y músicos, trabajadores de la cultura hacen más llevaderas las horas de internación de niños y adultos, muchas veces aligerando el peso de duros tratamientos en los que la vida o la muerte penden de un delgado hilo.

Una escena memorable de la peli, en la que brilla el inolvidable Robin Williams: https://www.youtube.com/watch?v=2MJgEfNYJjA..

La narración oral, territorio de encuentro y mancomunión

En ese mismo y en otros territorios asistenciales en los que campean dolores, sufrimientos y privaciones, encuentro el campo fértil para desplegar la disciplina en la que pongo en juego mi modo de comunicar y comunicarme con los otros.

Desde el ejercicio de acompañar a quien necesita un recreo en su abrumador contexto, un respiro lúdico o una desconexión momentánea y parcial de una realidad agobiante, mi práctica de la narración oral desgrana historias reveladoras en auditorios atravesados por la marginación y las postergaciones. 
Cárceles, institutos de menores, casas para adultos mayores, comedores y merenderos, las calles, escuelas o instituciones barriales son el ámbito en el que las palabras dichas fluyen, se entrelazan y tejen tramas de fantasías, deseos y fértiles encuentros.

Desde la literatura clásica hasta los textos de mi autoría, los cuentos atraviesan los sentidos de auditorios ávidos por incorporar a su bagaje historias que los interpelan, los representan, los contienen o los niegan.

Cada función dispara entre el público un vendaval de emociones, de representaciones simbólicas, de saltos hacia un más allá utópico, lejano pero asequible.

$Y$ en medio de esa habitualidad, de esa normalidad establecida por el sistema, se desata la pandemia de coranavirus y el mundo se pone patas para arriba. Borrón y cuenta nueva. A empezar todo de cero.

¿Cómo mantener viva la llama de la narración oral cuando no hay a mi lado un otro que escuche y sienta? ¿Cómo transmitir las sensaciones encerradas en palabras cuándo no puedo sentir ni ver la expresión del otro?

Es así que un arte acuñado por siglos en civilizaciones de todos los continentes, rompe los márgenes de la formalidad, sale de su formato presencial y cercano y se lanza al fascinante -y por momentos poco amigable- mundo de la virtualidad.

$\mathrm{Y}$ es así que me sumo las redes, no ya como soporte de mi tarea realizada, sino como mi territorio actual. Esas redes que están nutridas de las historias que cuentacuentos, narradores orales, juglares, artesanos y trabajadores de la palabra ponen a disposición de ese otro que necesita de nuestro arte para acercar y compartir sentimientos. Historias que nos recuerdan el 24 de marzo y salimos desde lo simbólico a marcar presencia, que conmemora el 2 de Abril y decimos presente, marchamos con las Madres de la Plaza cada jueves, o contamos para denunciar que las violencias hacia las mujeres, en esta cuarentena aumentan, siempre desde nuestro arte.

Y no es fácil, nadie nos dijo que lo seria, pero lo intentamos y lo logramos. A pesar de faltarnos esas miradas atentan a las que estamos acostumbrados y acostumbradas se traducen en corazoncitos, me gusta, o un ojito que se conecta en "un vivo" que decidimos hacer, sentimos que esa llama la estamos reavivando y el fogón que nos convoca desde tiempos inmemoriales vuelve a encenderse. 
Buscamos también nuevas formas de no detener el tiempo, de adaptar a estas épocas lo planeado. No suspender las rondas cuenteras, festivales, ciclos de narración y hacer cursos acelerados de plataformas para transmitir, hacer conferencias grupales y conectarnos. También de esta manera el mensaje rompe trabas y volamos desde nuestra casa a otras casas del planeta, coordinando horarios, tiempos y tecnologías.

No es fácil, tampoco resultó imposible, aunque cada vez que terminamos de "hacer un vivo" o de grabar un cuento para poder estar en este nuevo escenario digital, deseamos fuertemente que sea la última vez y que volvamos a tener frente a nosotros la irremplazable mirada que se encuentra con la nuestra y así poder confirmar una vez mas que cuando contamos, contamos con el otro.

Poema escrito en 1869 y que en 1919 volvió a tener vigencia por la pandemia de gripe española.

https://www.youtube.com/watch?v=2Sex1ya5Zic

Vivo de Pedro Aznar Mencionado en la Nota

https://www.facebook.com/15926481705/videos/2905477749545553/?v=29054777499545553

Cuento narrado para el espacio ECUNHI que cambió de modalidad por la Pandemia, realizándose el ciclo de manera virtual y que lleva cinco semanas con este formato.

https://www.facebook.com/ecunhi/videos/664028367750427/? tn_=kC-R\&eid=ARCGHE6C-

7yDVtwoMogNGqLs67PBm_deCSSfaeLRkLmX573pnubNibrl-

XouH8PZafgYo9n8hwnBDrod\&hc_ref=ARSnNZs1ISt2kNjqIE_kaqvRI2DjXXjsZBSRJ9PVZuCsL kaxPilul9pze5r-oz9hvbw\&fref=nf\&_xts_[0]=68.ARBwWl5asoslbpVO-

yYswkFMull3YtumgIK8clYXIWO1K26RpQkMUfwDQMFaVNgQ6hmh3tHK43leMqiDc7J80yLKc w-7BVmfmEYAI80oJNd-

plefxuUq53M7nJs3FdkYSChUYRNI8seDCHwa66nwfJd1j4BPwnP2YXcCwgqqBUeQ9va4dADO 35gDC92DHNFsMah-

5umte2IUQ2vSAS8HwET19j4t3d3pj_InxOE07AljkHpSKUDRhHRlycZj98kmHqoYFmW9jsow1N hBmep6zl16R9IR1cRIfUYRR2K1EyFliMQK6t-N-ryx1gDsY0tGsMBTPW-

Khe1SIQArnYdRcvCKgO35R_hXbf346w 